\title{
FAKTOR-FAKTOR MOTIVASI KERJA: SUPERVISI, PENGHASILAN, DAN HUBUNGAN INTERPERSONAL MEMENGARUHI KINERJA PERAWAT PELAKSANA
}

\author{
Yana Zahara ${ }^{1,2 *}$, Ratna Sitorus ${ }^{3}$, Luknis Sabri $^{4}$ \\ 1. RSPAD Gatot Soebroto Bagian Keperawatan, Jakarta 10410, Indonesia \\ 2. Program Studi Magister Fakultas Ilmu Keperawatan Universitas Indonesia, Depok 16424, Indonesia \\ 3. Fakultas Ilmu Keperawatan Universitas Indonesia, Depok 16424, Indonesia \\ 4. Fakultas Kesehatan Masyarakat Universitas Indonesia, Depok 16424, Indonesia \\ *Email: yana_zahara@yahoo.co.id
}

\begin{abstract}
Abstrak
Kinerja perawat berpengaruh langsung terhadap kualitas pelayanan kesehatan. Penelitian ini merupakan penelitian deskriptif kuantitatif dengan pendekatan cross sectional yang bertujuan untuk mengetahui hubungan faktor-faktor motivasi kerja dengan kinerja perawat pelaksana di ruang rawat inap Rumah Sakit X. Penelitian menggunakan proportionate random sampling yang telah memenuhi kriteria inklusi, yaitu 100 perawat pelaksana Rumah Sakit X. Hasil penelitian ini menunjukkan ada tiga subvariabel motivasi kerja yang ada hubungan signifikan dengan kinerja perawat yaitu: hubungan interpersonal $(\mathrm{OR}=4,345)$, supervisi $(\mathrm{OR}=72,952)$ dan penghasilan/gaji $(\mathrm{OR}=7,304)$. Sedangkan variabel karakteristik individu menunjukkan dua variabel yang ada hubungan signifikan dengan kinerja adalah pendidikan perawat pelaksana $(\mathrm{OR}=7,567)$ dan umur $(\mathrm{OR}=25,948)$. Adapun subvariabel yang dominan berhubungan dengan kinerja perawat adalah supervisi $(\mathrm{OR}=72,952)$, setelah dikontrol variabel umur, penghasilan/gaji dan tingkat pendidikan. Peningkatan supervisi oleh kepala ruangan, komite keperawatan, dan bagian keperawatan perlu untuk ditingkatkan, dengan cara pendekatan struktur organisasi agar dapat memotivasi kinerja perawat pelaksana.
\end{abstract}

Kata kunci: faktor-faktor motivasi kerja, kinerja perawat

\begin{abstract}
Performance of nurses directly affect to quality health care. Staff nurse is a contribution worker directly to the quality of the services for the client. The work motivation factor is one of factors which influence the work of nurse. This research is a descriptive quantitative by a cross sectional design which aiming to know relationship between the work motivation factors with staff nurse performance inpatient wards in Hospital X. Research used a proportionate random sampling which fulfilled an inclusion criterion; it was almost 100 staff nurse at inpatient wards in Hospital X. This research result indicated three sub variables of work motivation which related significantly by nurse performance including interpersonal relation (OR $=4.345)$, supervision $(O R=72.952)$ and incomes or salary $(O R=7.304)$. While individual characteristic variable indicated two variables which related significantly by performance is education of staff nurse $(O R=7.567)$ and age $(O R=25.948)$. There are dominant sub variable connected with staff nurse performance is supervision $(O R=72.952)$, after it was controlled by variables of age, incomes or salary and education level. Increase of supervision by head nurse, nursing committee, and nursing section need to be improved, with the approach of organizational structure in order to motivate the performance of nurses.
\end{abstract}

Keywords: factors of work motivation, nurse performance

\section{Pendahuluan}

Pelayanan keperawatan yang berkualitas sangat dipengaruhi kinerja perawat dalam bekerja. Kinerja profesional perawat adalah penampilan kerja perawat berdasar standar kinerja profesional yang disusun oleh PPNI (2004). Dewasa ini beberapa penelitian yang berkaitan dengan kinerja perawat telah banyak dilakukan. Fenomena yang ada menunjukkan masih banyak keluhan klien terhadap kualitas pelayanan yang kurang memuaskan. Kajian yang telah dilakukan Direktorat Pelayanan Keperawatan Depkes RI (2001) menunjukkan pelayanan keperawatan yang diberikan perawat kepada klien masih jauh dari harapan. Penelitian Sukoco (2001) terdapat $72,6 \%$ klien merasakan kualitas pelayanan keperawatan masih kurang baik. Selain itu, hasil penelitian oleh Rusmiati (2006) menunjukkan perawat pelaksana sebagian besar mempunyai kinerja kurang baik $(50,5 \%)$. 
Beberapa hasil kajian mengenai kinerja perawat menunjukkan kinerja perawat yang belum optimal. Fenomena ini tidak terlepas dari berbagai faktor yang saling mempengaruhi. Gibson, et al. (1996) menjelaskan bahwa terdapat 3 kelompok variabel yang dapat mempengaruhi perilaku kerja personel, yaitu: variabel individu, variabel organisasi, dan variabel psikologik. Ketiga variabel tersebut akan saling mempengaruhi, dan akan tercermin melalui perilaku kinerja seorang perawat.

Berbagai faktor yang mempengaruhi kinerja sangat menentukan terhadap hasil kerja perawat. Perhatian pada faktor psikologis perawat merupakan hal yang sangat penting antara lain persepsi perawat, sikap perawat, kepribadian perawat, belajar perawat, dan motivasi perawat terhadap pekerjaan yang dihadapainya. Variabel psikologis pada subvariabel motivasi merupakan salah satu variabel yang akan mempengaruhi kinerja perawat.

Rumah Sakit X merupakan rumah sakit tipe A di Indonesia dan menjadi pusat rujukan rumah sakit dibawahnya, sehingga RS X mempunyai tanggung jawab untuk memberikan pelayanan yang lebih baik dibanding dengan rumah sakit yang merujuk. Studi dokumentasi data kinerja RS X pada 2007 adalah kapasitas 741 tempat tidur. Ketenagaan, khususnya bagian keperawatan sejumlah 866 orang dengan kualifikasi SPK 203 orang (23,44\%), D III Keperawatan 633 orang $(73,09 \%)$, dan Strata satu keperawatan 30 orang $(3,47 \%)$.

Efesiensi pelayanan kesehatan dengan indikator BOR (Bed Occupancy Rate) 57,41\%, dan lama hari rawat LOS (Length Of Stay) 7,31. Hasil evaluasi Bagian Keperawatan Staf Direktur Pembinaan Pelayanan Medis (Bagwat Sdiryanmed) RS X pada 2007 yang dilakukan oleh peneliti, ditemukan bahwa penerapan standar dokumentasi asuhan keperawatan 71,20\%. Informasi lain dari hasil angket kepuasan klien sebesar 77,72\%. Kuesioner kepuasan kerja perawat menunjukkan hasil sebesar $74,46 \%$. Berdasarkan hal tersebut di atas dan untuk mengetahui lebih lanjut tentang motivasi kerja dan kinerja perawat pelaksana, maka dibuat rumusan masalah dan pertanyaan penelitian: "Bagaimana hubungan antara faktor-faktor motivasi kerja dengan kinerja perawat pelaksana?"

\section{Metode}

Penelitian ini menggunakan metode kuantitatif dengan pendekatan cross sectional, untuk melihat keadaan beberapa variabel dalam waktu tertentu dan pada saat tertentu (Sugiyono, 2007). Penelitian bertujuan untuk meneliti hubungan antara variabel independen dengan variabel dependen. Pada penelitian ini variabel independen adalah motivasi kerja, antara lain hubungan interpersonal, supervisi, kebijakan administrasi, kondisi kerja, penghasilan/ gaji, dan variable confounding (karakteristik perawat: umur, jenis kelamin, status perkawinan, pendidikan, lama kerja). Sedang variabel dependen adalah kinerja profesional perawat:, yaitu jaminan mutu, pendidikan, penilaian kinerja, kesejawatan, etik, kolaborasi, pemanfaatan sumber, dan riset.

Pada penelitian ini sampel penelitian menggunakan teknik proportionate random sampling yang telah memenuhi kriteria inklusi dan memberikan persetujuan menjadi responden, yaitu 100 perawat pelaksana di RS X. Analisis data univariat untuk menggambarkan karateristik variabel, baik variabel independen, variabel dependen, maupun variable confounding. Pada analisis yang akan dilihat adalah gambaran distribusi frekuensi responden berdasar variabel yang diteliti, yaitu variabel kinerja dan motivasi kerja serta variable counfounding.

Analisis bivariat dilakukan untuk mengetahui hubungan masing-masing variabel independen dan variable confounding dengan variabel dependen menggunakan uji Chi-square. Analisis multivariat untuk mengetahui subvariabel independen dan variable confounding dengan variabel dependen (kinerja perawat). Uji statistik yaitu menggunakan analisis regresi logistik ganda.

\section{Hasil}

\section{Karaktristik Individu}

Hasil penelitian menunjukkan rerata 34 tahun, 74\% perawat berumur $\geq 34$ tahun dan $26 \%$ berumur 
Tabel 1. Distribusi Perawat Berdasarkan Karakteristik Individu

\begin{tabular}{lcc}
\hline \multicolumn{1}{c}{ Karakteristik Individu } & Frekuensi & Prosentase (\%) \\
\hline Umur & 74 & $74 \%$ \\
a. $=34$ tahun & 26 & $26 \%$ \\
b. $<34$ tahun & & \\
Jenis Kelamin & 17 & $17 \%$ \\
a. Laki-laki & 83 & $83 \%$ \\
b. Perempuan & & \\
Status Perkawinan & 83 & $83 \%$ \\
a. Menikah & 17 & $17 \%$ \\
b. Belum Menikah & & \\
Pendidikan & 19 & $19 \%$ \\
a. SPK & 81 & $81 \%$ \\
b. D III Kep/S1 Kep & & \\
Lama Kerja & 65 & $35 \%$ \\
a. $\geq 11$ tahun & 35 & \\
b. < 11 tahun & & \\
\hline
\end{tabular}

$<34$ tahun. Jenis kelamin perawat $83 \%$ perempuan dan $17 \%$ laki-laki, sedangkan status perkawinan $83 \%$ sudah menikah dan $17 \%$ belum menikah. Tingkat pendidikan perawat yaitu $81 \%$ DIII/ S1 Keperawatan dan $19 \%$ SPK. Lama kerja perawat rerata 11 tahun, dengan $65 \%$ lama kerja $\geq 11$ tahun dan 35\% lama kerja $<11$ tahun (lihat tabel 1).

\section{Motivasi Kerja dan Kinerja Perawat}

Hasil penelitian menunjukkan bahwa 59\% perawat pelaksana memiliki motivasi kerja yang baik, sedangkan $41 \%$ memiliki motivasi kerja kurang. Selain itu, hasil menunjukkan bahwa $61 \%$ perawat pelaksana memiliki kinerja baik, sedangkan 39\% memiliki kinerja kurang (tabel 2).

\section{Hubungan Faktor-Faktor Motivasi Kerja dengan Kinerja Perawat}

Tabel 3 menunjukkan 73,4\% perawat pelaksana yang mempersepsikan hubungan interpersonal harmonis yang kinerjanya baik, lebih besar dari yang mempersepsikan hubungan interpersonal kurang harmonis $(40,0 \%)$. Hasil uji statistik menyimpulkan adanya hubungan yang bermakna antara hubungan interpersonal dengan kinerja $(\mathrm{p}=$ $0,001 ; \alpha=0,05)$. Hasil analisis menunjukkan bahwa perawat yang mempersepsikan hubungan interpersonal yang harmonis berpeluang berkinerja baik 4,345 kali dibanding perawat yang memiliki hubungan interpersonal yang kurang harmonis $(\mathrm{OR}=4,345 ; 95 \% \mathrm{CI}: 1,820-10,369)$.

Hasil penelitian menunjukkan $85,9 \%$ perawat mempersepsikan supervisi baik yang kinerjanya baik lebih besar daripada yang mempersepsikan supervisi kurang $(16,6 \%)$. Hasil dari uji statistik menunjukkan bahwa ada perbedaan kinerja perawat antara yang mempersepsikan supervisi baik dan supervisi kurang $(p=0,000 ; \alpha=0,05)$. Hasil juga menunjukkan bahwa perawat pelaksana yang mempersepsikan supervisi yang baik berpeluang 
berkinerja baik 30,556 kali dibandingkan yang mempersepsikan supervisi kurang $(\mathrm{OR}=30,556$; 95\% CI : 9,923-94,090).

Hasil penelitian ini menunjukkan bahwa sebesar $62,1 \%$ perawat yang mempersepsikan kebijakan administrasi kondusif dengan kinerjanya baik lebih besar daripada yang mempersepsikan kebijakan administrasi tidak kondusif (57,6\%). Hasil uji statistik diperoleh bahwa kebijakan administrasi tidak ada hubungan yang bermakna dengan kinerja $(p=0,430 ; \alpha=0,05)$. Selain itu, hasil menunjukkan bahwa sebesar $63,6 \%$ perawat mempersepsikan kondisi kerja kondusif, sedangkan sebesar 52,1\% yang mempersepsikan kondisi kerja tidak kondusif. Hasil uji statistik didapatkan bahwa kondisi kerja tidak ada hubungan yang bermakna dengan kinerja $(p=0,227 ; \alpha=0,05)$.

Hasil penelitian menunjukkan $83,3 \%$ perawat yang mempersepsikan penghasilan/gaji yang mencukupi dengan kinerjanya baik lebih besar daripada yang mempersepsikan penghasilan/gaji tidak mencukupi $(40,3 \%)$. Hasil uji statistik menyimpulkan bahwa ada hubungan yang bermakna antara penghasilan/ gaji dengan kinerja perawat $(p=0,000 ; \alpha=0,05)$. Hasil juga menunjukkan bahwa perawat yang mempersepsikan penghasilan/gaji yang mencukupi mempunyai peluang berkinerja baik sebesar 7,381 kali dibandingkan dengan yang mempersepsikan penghasilan/gaji tidak mencukupi $(\mathrm{OR}=7,381$; 95\% CI : 2,664-18,890).

Tabel 2. Distribusi Perawat Berdasarkan Motivasi Kerja, Kinerja, dan Faktor-faktor Motivasi

\begin{tabular}{lcc}
\hline \multicolumn{1}{c}{ Variabel } & Frekuensi & Persentase (\%) \\
\hline Motivasi Kerja & & 59 \\
a. Baik & 59 & 41 \\
b. Kurang & & \\
Kinerja & 61 & 61 \\
a. Baik & 39 & 39 \\
b. Kurang & & \\
Faktor-faktor Motivasi Kerja & & 47 \\
Hubungan interpersonal & & 53 \\
a. Harmonis & 47 & \\
b. Kurang harmonis & 53 & 64 \\
Supervisi & & 36 \\
a. Baik & 64 & \\
b. Kurang & 36 & 74 \\
Kebijakan administrasi & & 26 \\
a. Lengkap & & \\
b. Kurang lengkap & 74 & 77 \\
Kondisi kerja & 26 & 23 \\
a. Kondusif & & \\
b. Kurang kondusif & 77 & \\
Penghasilan/gaji & 23 & \\
a. Mencukupi & & \\
b. Kurang mencukupi & 48 & \\
\hline
\end{tabular}




\section{Hubungan Karakteristik Individu dengan Kinerja Perawat}

Tabel 4 menunjukkan sebesar $72,6 \%$ perawat berumur $\geq 34$ tahun kinerjanya baik, lebih besar dibandingkan dengan yang berumur $<34$ tahun (71,4\%). Hasil uji statistik disimpulkan bahwa umur tidak ada hubungan dengan kinerja $(\mathrm{p}=0,059$; $\alpha=0,05)$. Hasil juga menunjukkan bahwa $62,6 \%$ perawat pelaksana perempuan kinerjanya baik, lebih besar dibandingkan dengan perawat laki-laki $(52,9 \%)$.

Hasil uji statistik dapat disimpulkan bahwa jenis kelamin tidak ada hubungan dengan kinerja $(\mathrm{p}=$ $0,314 ; \alpha=0,05)$. Selain itu, hasil menunjukkan bahwa sebesar $61,4 \%$ perawat pelaksana yang sudah menikah dengan kinerjanya baik, lebih besar dibanding dengan yang belum menikah $(58,8 \%)$. Hasil uji statistik menunjukkan status perkawinan tidak ada hubungan dengan kinerja $(\mathrm{p}=0,321$; $\alpha=0,05)$.

Hasil penelitian ini menunjukkan bahwa sebesar $66,6 \%$ perawat dengan latar belakang pendidikan DIII/S1 Keperawatan yang kinerjanya baik, lebih besar dibandingkan dengan yang berpendidikan SPK/SPR (36,6\%). Hasil uji statistik didapatkan bahwa terdapat hubungan yang bermakna antara pendidikan dengan kinerja $(\mathrm{p}=0,017 ; \alpha=0,05)$.

Hasil menunjukkan perawat berpendidikan DIII/ S1 Keperawatan berpeluang berkinerja baik 3,429 kali dibandingkan yang berpendidikan SPK/SPR (OR 3,429; 95\% CI : 1,211-9,704). Hasil penelitian menunjukkan $61,5 \%$ perawat dengan lama kerja $\geq$ 11 tahun kinerjanya baik, lebih besar dibanding dengan lama kerja $<11$ tahun $(60,0 \%)$. Hasil uji statistik menyimpulkan bahwa lama kerja tidak berhubungan dengan kinerja $(p=0,524 ; \alpha=0,05)$. Tabel 4 menunjukkan bahwa supervisi merupakan faktor yang paling dominan berhubungan dengan kinerja. Hasil analisis menunjukkan bahwa perawat dengan supervisi yang baik akan berpeluang memiliki kinerja yang baik 72,952 kali dibanding dengan perawat yang supervisi kurang baik (OR= 72,952).

\section{Pembahasan}

\section{Hubungan Karakteristik Individu dengan Kinerja}

Hasil penelitian menunjukkan bahwa perawat yang berumur $\geq 34$ tahun berpeluang berkinerja baik 25,848 kali dibanding dengan perawat umur $<34$ tahun. Hal ini sesuai pendapat Wursanto (2003), bahwa produktifitas akan meningkat antara umur 20 - 45 tahun. Siagian (2005) menjelaskan umur berkaitan erat dengan kedewasaan atau maturitas seseorang, bahwa semakin tinggi umur seseorang, kedewasaan teknis, dan psikologisnya juga semakin tinggi. Menurut Gibson (1987, dalam Ilyas, 2002), bahwa umur mempengaruhi kinerja individu.

Hasil penelitian menunjukkan perawat pelaksana perempuan kinerja baik lebih besar dibanding lakilaki. Sesuai dengan penelitian Nurhaeni (2001) terhadap perawat menunjukkan secara proporsional bahwa perawat perempuan kinerjanya lebih baik dibanding laki-laki. Selain itu, hasil didapatkan jenis kelamin tidak ada hubungan bermakna dengan kinerja. Hipotesis penelitian tidak terbukti, analisis ini sejalan dengan hasil riset oleh Robbins (2006) yang mengatakan hanya ada sedikit perbedaan penting antara laki-laki dan perempuan yang mempengaruhi kinerja mereka.

Hasil penelitian menunjukkan bahwa tidak ada hubungan antara status perkawinan dengan kinerja. Menurut Nurhaeni (2001), bahwa karyawan yang sudah menikah mempunyai tingkat keabsenan dan pengunduran diri lebih rendah, dan lebih puas dengan pekerjaannya daripada rekan kerja yang tidak menikah. Sejalan dengan pendapat Siagian (2005), status perkawinan berpengaruh terhadap perilaku karyawan dalam kehidupan organisasinya, secara positif maupun negatif. Menurut Robbins (2002), bahwa status perkawinan menimbulkan peningkatan tanggung jawab sehingga pekerjaan menjadi lebih berharga dan penting. Situasi tersebut dapat meningkatkan motivasi kerja dan akhirnya mempengaruhi tingkat keberhasilan kerja.

Pada penelitian ini perawat dengan latar belakang pendidikan DIII/ S1 Keperawatan mempunyai 
Tabel 3. Hasil Uji Statistik Faktor Motivasi dengan Kinerja Perawat Pelaksana

\begin{tabular}{|c|c|c|c|c|c|c|c|}
\hline \multirow{3}{*}{$\begin{array}{c}\text { Komponen } \\
\text { Moti vasi Kerja }\end{array}$} & \multicolumn{4}{|c|}{ Kinerja Perawat } & \multirow{3}{*}{ Total } & \multirow{3}{*}{$\mathbf{p}$} & \multirow{3}{*}{$\begin{array}{c}\text { OR } \\
95 \% \mathrm{CI} \\
\end{array}$} \\
\hline & \multicolumn{2}{|c|}{ Baik } & \multicolumn{2}{|c|}{ Kurang } & & & \\
\hline & $\mathbf{n}$ & $\%$ & $\mathbf{n}$ & $\%$ & & & \\
\hline \multicolumn{8}{|l|}{ Hubungan interpersonal } \\
\hline a. Harmonis & 47 & 73,4 & 17 & 26,6 & 64 & & 4,345 \\
\hline b. Kurang harmonis & 14 & 40,0 & 22 & 60,0 & 35 & 0,001 & $(1,820-10,369)$ \\
\hline Supervisi & & & & & & & 30,556 \\
\hline a. Baik & 55 & 85,9 & 9 & 24,1 & 64 & 0,000 & $(9,923-94,090)$ \\
\hline b. Kurang & 6 & 16,6 & 30 & 83,3 & 36 & & \\
\hline \multicolumn{8}{|l|}{ Kebijakan admini strasi } \\
\hline a. Kondusif & 46 & 62,1 & 28 & 47,9 & 74 & 0,430 & 1,205 \\
\hline b. Tidak kondusif & 15 & 57,6 & 11 & 32,4 & 26 & & $(0,485-2,990)$ \\
\hline \multicolumn{8}{|l|}{ Kondisi kerja } \\
\hline a. Kondusif & 49 & 63,6 & 28 & 36,4 & 77 & 0,227 & 1,604 \\
\hline b. Tidak kondusif & 12 & 52,1 & 11 & 47,9 & 23 & & $(0,626-4,110)$ \\
\hline Penghasilan/gaji & & & & & & & 7,381 \\
\hline a. Mencukupi & 40 & 83,3 & 8 & 16,7 & 48 & 0,000 & $(2,664-18,890)$ \\
\hline b. Tidak mencukupi & 21 & 40,3 & 31 & 59,7 & 52 & & \\
\hline
\end{tabular}

peluang berkinerja baik 7,074 kali dibandingkan dengan latar belakang pendidikan SPK/ SPR. Hal ini sesuai dengan pendapat Gillies (2002), perawat dengan pendidikan tinggi mempunyai kemampuan kerja yang lebih tinggi. Gibson, et al. (1996) juga mengemukakan bahwa tingkat pendidikan yang tinggi umumnya menyebabkan seseorang lebih mampu dan bersedia menerima tangung jawab. Lebih lanjut Ilyas (2002) memaparkan bahwa pendidikan merupakan gambaran kemampuan dan keterampilan individu, adalah faktor utama yang dapat memengaruhi kinerja. Melalui pendidikan seseorang dapat meningkatkan kematangan intelektual sehingga dapat membuat keputusan dalam bertindak. Selain itu, diasumsikan bahwa seseorang yang memiliki latar belakang pendidikan tinggi mempunyai tujuan, harapan, dan wawasan meningkatkan prestasi kerja melalui kinerja optimal.
Hasil penelitian menunjukkan tidak ada hubungan yang bermakna antara lama kerja dengan kinerja. Menurut Siagian (2005), semakin lama seseorang berkarya dalam suatu organisasi semakin tinggi produktivitasnya karena karyawan semakin berpengalaman dan memiliki keterampilan dalam tugas. Robbins (2006) mengungkapkan masa kerja dan kepuasan saling berkaitan positif, semakin lama seorang bekerja, maka semakin terampil dan berpengalaman pula melaksanakan pekerjaannya.

\section{Hubungan Faktor-Faktor Motivasi Kerja Perawat dengan Kinerja}

Hasil penelitian menunjukkan bahwa hubungan interpersonal yang harmonis akan memberikan kepuasan terhadap teman sekerja yang dapat meningkatkan kinerja. Hal ini sesuai dengan pendapat Robbins (1991, dalam Soeroso, 2003) tentang kepuasan terhadap teman sekerja, bahwa 
sejah mana teman sekerja dapat mendukung dan memberikan perhatian, menyenangkan, dan secara teknis mampu melaksanakan tugas-tugas.

Hasil penelitian juga menunjukkan ada hubungan bermakna antara hubungan interpersonal dengan kinerja. Sejalan dengan pendapat Rakhmat (2000), semakin baik hubungan interpersonal seseorang maka semakin terbuka mengungkapkan dirinya dan semakin cermat mempersepsikan mengenai orang lain dan diri sendiri, sehingga semakin efektif komunikasi yang berlangsung antara komunikan. Hubungan interpersonal yang harmonis antara atasan dan bawahan serta tim kesehatan akan berpotensi dalam mendorong, menggerakan, dan memelihara perilaku seseorang dari luar individu (faktor eksternal) untuk melaksanakan pekerjaan mencapai tujuan yang telah ditetapkan.
Hasil penelitian menunjukkan faktor yang dominan berhubungan dengan kinerja yaitu supervisi. Locke dalam Munandar (2004) mengungkapkan bahwa hubungan karyawan dengan supervisor diwarnai oleh hubungan fungsional dengan mencerminkan sejauh mana supervisor membantu perawat untuk memuaskan nilai-nilai pekerjaan yang penting bagi tenaga kerja. Sejalan dengan Widaningsih (2002) yang menyatakan ada hubungan yang bermakna antara supervisi kepala ruangan dengan kinerja perawat $(\mathrm{p}=0,0001)$.

Supervisi yang terencana pada standar praktik yang berlaku menjamin kualitas asuhan keperawatan kepada pasien yang diberikan oleh perawat. Oleh karena itu, supervisi yang baik akan menimbulkan motivasi kerja perawat dan akan meningkatkan kinerja perawat.

Tabel 4. Distribusi responden berdasarkan karakteristik dan kinerja perawat

\begin{tabular}{|c|c|c|c|c|c|c|c|}
\hline \multirow{3}{*}{ Karakteristik Individu } & \multicolumn{4}{|c|}{ Kinerja Perawat } & \multirow{3}{*}{ Total } & \multirow{3}{*}{$\mathbf{p}$} & \multirow{3}{*}{$\begin{array}{c}\text { OR } \\
95 \% \mathrm{CI}\end{array}$} \\
\hline & \multicolumn{2}{|c|}{ Baik } & \multicolumn{2}{|c|}{ Kurang } & & & \\
\hline & $\mathbf{n}$ & $\%$ & $\mathbf{n}$ & $\%$ & & & \\
\hline \multicolumn{8}{|l|}{ Umur } \\
\hline a. $\geq 34$ tahun & 49 & 72,6 & 25 & 17,4 & 74 & 0,059 & 2,287 \\
\hline b. $<34$ tahun & 12 & 71,4 & 14 & 18,6 & 26 & & $(0,921-5,676)$ \\
\hline Jenis Kelamin & & & & & & & 1,491 \\
\hline a. Perempuan & 52 & 62,6 & 31 & 37,4 & 83 & 0,314 & $(0,521-4,266)$ \\
\hline b. Laki-laki & 9 & 52,9 & 8 & 47,1 & 17 & & \\
\hline \multicolumn{8}{|l|}{ Status Perkawinan } \\
\hline a. Menikah & 51 & 61,4 & 32 & 38,6 & 83 & 0,321 & 1,156 \\
\hline b. Belum Menikah & 10 & 58,8 & 7 & 42,2 & 17 & & $(0,567-4,299)$ \\
\hline \multicolumn{8}{|l|}{ Pendidikan } \\
\hline a. D III Kep/S1 Kep & 54 & 66,6 & 27 & 33,4 & 81 & 0,017 & 3,429 \\
\hline b. SPK/SPR & 7 & 36,8 & 12 & 63,2 & 19 & & $(1,211-9,704)$ \\
\hline \multicolumn{8}{|l|}{ Lama Kerja } \\
\hline a. $\geq 11$ tahun & 40 & 61,5 & 25 & 38,5 & 65 & 0,524 & 1,067 \\
\hline b. $<11$ tahun & 21 & 60,0 & 14 & 40 & 35 & & $(0,460-2,473)$ \\
\hline
\end{tabular}


Hasil analisis yang diperoleh bahwa 74\% perawat mempersepsikan kebijakan administrasi lengkap. Hal ini sejalan dengan pendapat Azwar (1996) mengemukakan kebijakan yang kondusif akan memberikan dampak positif terhadap kinerja karyawan. Hasil analisis hubungan kebijakan administrasi dengan kinerja menunjukkan bahwa kebijakan administrasi tidak ada hubungan yang bermakna dengan kinerja.

Kelengkapan standar dan sosialisasi terhadap karyawan rumah sakit secara terus menerus akan dapat meningkatkan pemahaman staf. Kondisi yang mendorong, menggerakkan, dan memelihara perilaku seseorang dari luar (faktor eksternal) akan melaksanakan pekerjaan mencapai tujuan yang telah ditetapkan, karena adanya aturan, pedoman kerja yang lengkap.

Hasil analisis didapatkan bahwa sebesar $77 \%$ perawat mempersepsikan kondisi kerja kondusif. Sesuai dengan pendapat dari Gauci dan Norman (1997, dalam Lovegren, Rasmussen, dan Engstrom, 2002) yang mengemukakan bahwa kondisi kerja yang baik dapat meningkatkan kualitas hidup dalam bekerja yang akan berdampak terhadap produktivitas kerja tenaga kesehatan profesional yang baik pula.

Hasil penelitian menunjukkan kondisi kerja tidak ada hubungan signifikan dengan kinerja. Hal ini kemungkinan perawat pelaksana yang kondisi kerja kondusif akan berkinerja baik dan ada yang kondisi kerja tidak kondusif tetap berkinerja baik. Situasi ini sebagai gambaran bahwa motivasi kerja perawat untuk bekerja akan lebih baik lagi bila didukung dengan kondisi kerja yang kondusif, sehingga kinerja perawat akan meningkat yang berdampak pelayanan dan asuhan keperawatan akan berkualitas.

Hasil penelitian menunjukkan bahwa perawat yang mempersepsikan penghasilan/gaji yang mencukupi berpeluang berkinerja baik 7,304 kali dibanding yang mempersepsikan gaji tidak mencukupi. Hasil penelitian ini sesuai pendapat Harder (1992, dalam Panggabean, 2004), yang memaparkan bahwa gaji merupakan jenis penghargaan yang paling penting dalam organisasi.

Menurut Hill, Bergma, dan Scarpello (1994, dalam Panggabean, 2004) yang juga mengungkapkan bahwa penghargaan yang diberikan mempunyai tujuan untuk menarik karyawan dalam jumlah dan kualitas yang diinginkan, mendorong agar lebih berprestasi, dan agar dapat mempertahankan mereka. Beberapa peneliti mengungkapkan bahwa penghargaan dapat memengaruhi tingkat motivasi karyawan (Lawler, 1973; Vroom, 1964, dalam Panggabean, 2004). Hal ini perlu perhatian dari pimpinan rumah sakit agar ada upaya untuk meningkatkan penghasilan.

Hasil penelitian menunjukkan bahwa sebesar $61 \%$ perawat pelaksana memiliki motivasi kerja yang baik. Hal ini sesuai dengan pernyataan Hasibuan (2003), bahwa motivasi merupakan hal yang menyebabkan, menyalurkan, dan mendukung perilaku manusia supaya mau bekerja giat dan antusias dalam mencapai hasil yang maksimal.

Tabel 5. Analisis multivariat regresi logistik supervisi, gaji, umur dan pendidikan dengan kinerja perawat pelaksana

\begin{tabular}{lcccccc}
\hline \multicolumn{1}{c}{ Variabel } & B & SE & Wald & Sig & OR & 95\% CI \\
\hline Supervisi & 4,290 & 0,908 & 22,330 & 000 & 72,952 & $12,312-432,269$ \\
Gaji & 1,988 & 0,697 & 8,142 & 0,004 & 7,304 & $01,864-28,624$ \\
Umur & 3,256 & 1,024 & 10,117 & 0,001 & 25,948 & $3,489-192.966$ \\
Pendidikan & 2,024 & 0,929 & 18,144 & 0,029 & 7,567 & $1,224-46,768$ \\
Constanta & $-18,409$ & 4,322 & 18,144 & 000 & 000 & \\
\hline
\end{tabular}

-2 Log-likelihood $=60,116 \quad \mathrm{p}=0,000$ 
Hasil penelitian faktor-faktor motivasi; manajer perawat yang tidak dapat memotivasi bawahan akan menyebabkan kinerja mereka menjadi buruk sehingga akibatnya adalah produktivitas mereka kemungkinan besar juga buruk (La Monica, 1998). Penelitian Hersey dan Blanchard (1977, dalam La Monica, 1998) yang menjelaskan bahwa sebesar $60 \%$ penampilan kerja karyawan dapat dipengaruhi oleh motivasi kerjanya.

Penelitian Nurhaeni (2003) tentang kinerja perawat Rumah Sakit Jiwa Makasar mengemukakan ada hubungan bermakna motivasi dengan kinerja, yaitu perawat dengan motivasi lebih tinggi berpeluang kinerja lebih baik 1,87 kali dari motivasi rendah. Hal ini menunjukkan bahwa perlunya pimpinan keperawatan meningkatkan motivasi kerja perawat pelaksana.

\section{Kesimpulan}

Hasil penelitian menunjukkan bahwa karakteristik perawat pelaksana dengan kinerja perawat di ruang rawat inap RS yang mempunyai hubungan yang bermakna adalah pendidikan dan umur, sedangkan faktor yang tidak ada hubungan yang bermakna meliputi jenis kelamin, status perkawinan dan lama kerja. Faktor-faktor motivasi dengan kinerja perawat pelaksana di ruang rawat inap yang paling dominan memiliki hubungan yang bermakna yaitu supervisi. Sedang, faktor yang tidak ada hubungan yang bermakna yaitu meliputi; kondisi kerja, dan kebijakan administrasi.

Peningkatan supervisi oleh kepala ruangan, komite keperawatan, dan bagian keperawatan perlu untuk ditingkatkan, dengan cara pendekatan struktur organisasi. Peningkatkan insentif dari pengelolaan sumber dana hasil usaha yang berasal dari swasta yang didistribusikan secara adil dan merata pada perawat yang bertugas di pelayanan klien. Selain itu, dinas atau bertugas dengan mempetimbangkan beban tugas yang diberikan terhadap perawat perlu diperhatikan.

Hubungan interpersonal antara perawat dengan teman sekerja, atasan, bawahan, dan tim kesehatan lain perlu diciptakan, yaitu dengan cara pertemuan berkala, seperti pertemuan ilmiah. Sehingga dapat terjalin komunikasi efektif untuk menyelesaikan masalah kesehatan pasien. Disamping itu, bagi penelitian selanjutnya yaitu diharapkan agar dapat memperhatikan aspek lain dari faktor-faktor motivasi kerja yang belum dilakukan oleh peneliti dalam penelitian ini seperti faktor-faktor motivasi internal individu (MS, JS, TN).

\section{Referensi}

Azwar, A. (1996). Menjaga mutu pelayanan kesehatan: Aplikasi prinsip lingkaran pemecahan masalah. Jakarta: Pustaka Sinar Harapan.

Gibson, J.L., et al. (1996). Organisasi-perilaku, struktur, \& proses (Edisi ke-8). Jakarta: Aksara Pratama.

Gillies, D.A. (2002). Nursing management: A system approach (3rd Ed.). Philadelphia: W.B. Saunders Company.

Hasibuan, M. (2003). Manajemen sumber daya manusia. Jakarta: Bumi Aksara.

Ilyas, Y. (2002). Kinerja: Teori, penilaian, \& penelitian. Jakarta: Badan penerbit Fakultas Kesehatan Masyarakat Universitas Indonesia.

La Monica, E.L. (1998). Kepemimpinan \& manajemen keperawatan: Pendekatan berdasarkan pengalaman. Jakarta: Penerbit EGC.

Nurhaeni. (2001). Faktor-faktor determinan yang berhubungan dengan kinerja perawat pelaksana di Rumah Sakit Jiwa Makasar (Tesis Master, Tidak dipublikasikan). Fakultas Ilmu Keperawatan Universitas Indonesia, Jakarta.

Panggabean, M.S. (2004). Manajemen sumber daya manusia. Bogor: Penerbit Ghalia Indonesia.

Persatuan Perawat Nasional Indonesia (PPNI). (2004). Standar praktik keperawatan. Jakarta: Pokja standar praktik keperawatan.

Rakhmat, J. (2000). Psikologi komunikasi. Bandung: Penerbit PT Remaja Rosdakarya. 
Robbins, S.P. (2006). Perilaku organisasi (Edisi kesepuluh). Jakarta: PT Indeks kelompok Gramedia.

Rusmiati. (2006). Hubungan lingkungan organisasi dan karakteristik perawat dengan kinerja perawat pelaksana di ruang rawat inap RSUP Persahabatan Jakarta (Tesis Master, Tidak dipublikasikan). Fakultas Ilmu Keperawatan Universitas Indonesia, Jakarta.

Siagian, S.P. (2005). Manajemen sumber daya manusia. Jakarta: PT Bumi Aksara.
Sukoco, A.S. (2001). Perbedaan persepsi perawat dengan klien terhadap kualitas pelayanan keperawatan di RSPAD Gatot Soebroto Jakarta (Tesis Master, Tidak dipublikasikan). Fakultas Ilmu Keperawatan Universitas Indonesia, Jakarta.

Widaningsih. (2002). Faktor-faktor yang berhubungan dengan kinerja perawat pelaksana di RSPAD Gatot Soebroto Jakarta (Tesis Master, Tidak dipublikasikan). Fakultas Ilmu Keperawatan Universitas Indonesia, Jakarta. 